\title{
The Paper Life of Building: Performative intra-action
}

\author{
Simon Twose and Jan Smitheram
}

\section{Introduction}

Drawing in architecture is conventionally understood as representation of built form. Representational thinking fixes the world as an object and resource for human subjects. In drawing, this means the creation of distance and a disconnection between the subject and the object of drawing. Robin Evans, for example, describes drawing as a mode of representational thinking expressed through its "disengagement, obliqueness, abstraction, mediation and action at a distance" (1997: 160). This separation between subject and object, for Evans, renders drawing a "disembodied mode of activity" (Evans 1997: 160). In his consideration of drawing, he argues that to free drawing from representation is to put into question the movement from drawing to building. His writing has provided leverage for subsequent writers to argue for a distinctiveness between drawing and building, to open drawing out to creative freedom, once it is lifted from the burden of the built and the burden of representation. This paper approaches the question of representation through a performative framework where the separation between the body, the object and the built is put into question. A building, the White-House designed by Simon Twose, will form the armature for a discussion of drawing and building in these terms. The White-House was a transitional project in that it began with an interest in representation, and was embedded within an Evans mode of understanding drawing, but during the process moved away from questions of representation towards a more performative mode.

The White-House project began as a response to Auckland, and looked at the city as an aesthetic phenomenon, as a suburban landscape of complex domestic influences flowing over an apparently complicit topography. I (Twose) argued that the suburbs, the landscape, and Auckland's architectural identity were all part of a complicated inter-connected economy. In the design process, the drawings and the subsequent building were seen as responsive to domestic influence, and to parallel larger domestic flows and influences in the action of the city; the design aestheticised on a small scale what the thin suburban field was doing at the scale of landscape. The drawing process, in this sense, was a representational lens in which to view Auckland, and the design developed notions of thinness, responsiveness and lack of fixity in material and position, drawn from observations of the city. Curved freehand drawings and a curved building resulted, and during the drawing process, an interest in flow merged with performative flows, in drawing and building.

The first part of the paper introduces, briefly, theories of performance and performativity. In the second part of the paper, the White-House is used to illustrate and extend an understanding of drawing as performative. In this

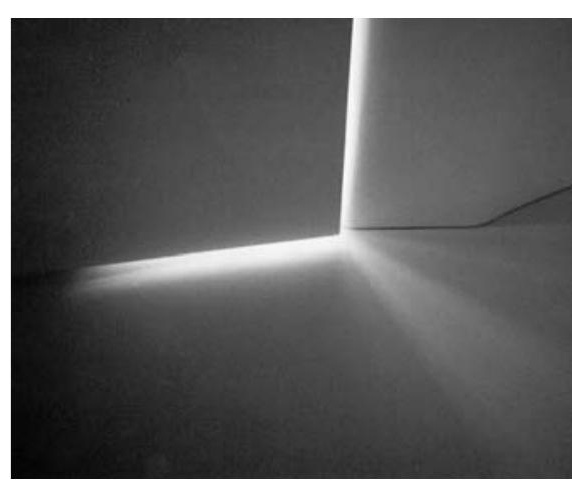

Detail, curved door jamb. 


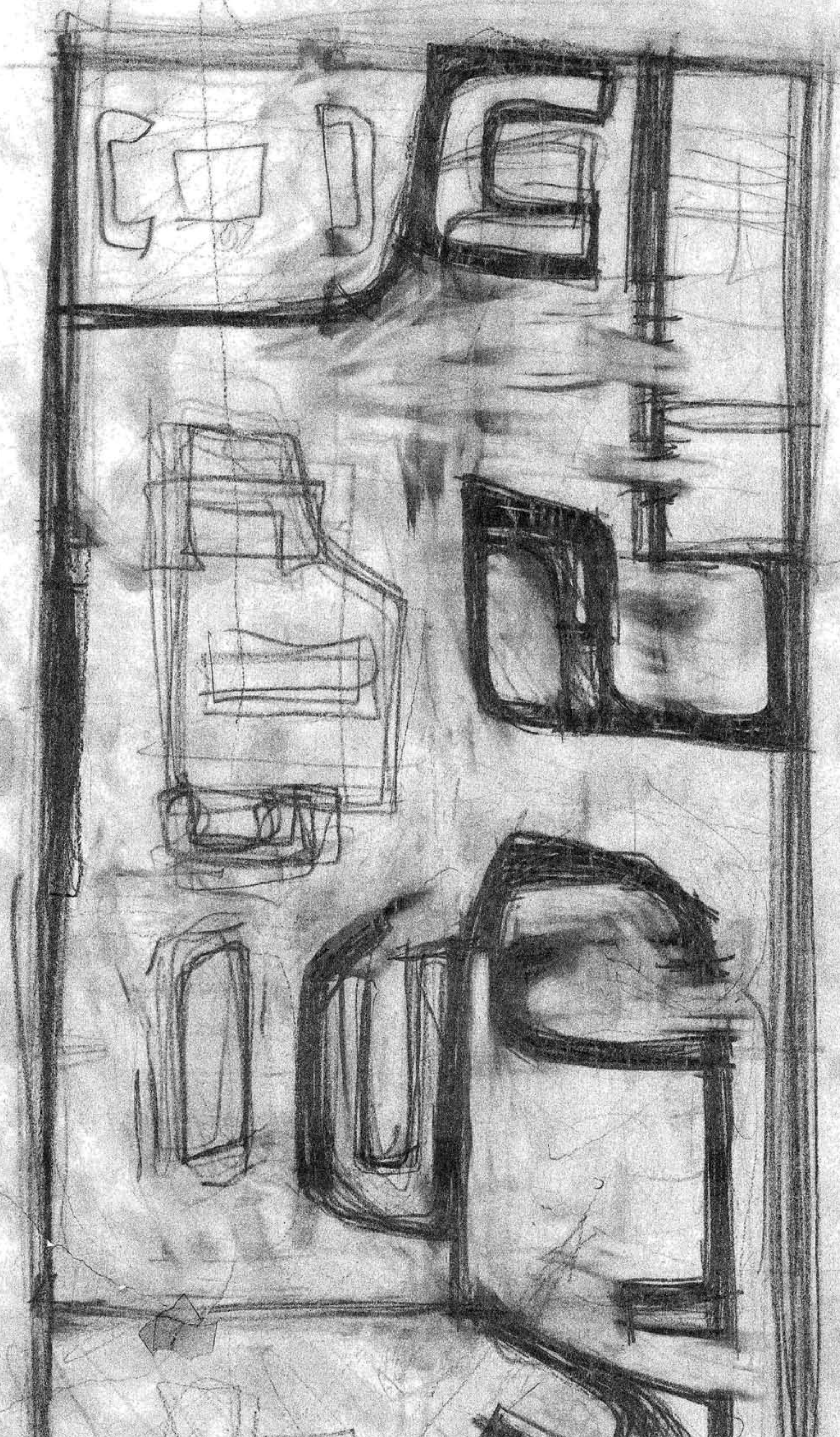


performative framework it is argued that, rather than framing representation as the only way knowledge can be extracted from the world, relations are reanimated by highlighting performative dimensions of drawing, and its relationships with the body and the built. The final part of the paper concludes that this re-working of the performative, within the context of drawing, focuses our attention on the assemblage of relations and intra-actions between drawing, building, the body and representation, and reveals them to be located, complexly, within and through each other.

\section{Performance and performativity}

The shift towards performance and performativity is more commonly referred to as the performative "turn", which loosely refers to the different apprehensions of the performative (Conquergood 2002, Denzin 2001, Nash 2000, Walker 2003, Thrift \& Dewsbury 2000, McCormack 2005, Madison \& Hamera 2006). Performance has its genus in theatre. However, while the notion of theatre still has a place in the study of performance, within the humanities, notions of performance have extended beyond theatrical metaphors. Performativity has its origins in the philosophical discussions of John L. Austin, particularly in his work on speech act theory; speech as not only describing an act, but in itself performing an action. Performance and performativity, within the so-called performative turn, have generally been collapsed, despite their different origins, and are often interchanged and used at cross purposes. This is manifest in the continual rendering of performativity through the lens of performance (Steiner 2003: 187, Butler 1993, Campbell 1992, Nicholson \& Seidman 1995, Parker \& Kosofsky 1995). Within architecture, this shift to understand drawing, the built form and occupation through performative understandings is seen, for example, in the works of Jane Tormey, Peter Wood, Neal Leach and Iain Borden. This paper is grounded in such debates, which shift towards considering processual and performative relations between architecture and the body; but we also move towards a composite of performance and performativity to describe the complex and dynamic relations of drawing. In this paper we argue that interleaving these two terms allows a productive way to approach the complexity of drawing practice, where discursive and embodied acts inherently cross.

The performative discussion within drawing is already a story of differentiation: for Tormey, we need to differentiate between the terms "performance" and "performative" (Tormey 2010); for Wood, we need to sever the connection with the built to completely consider the performative (Wood 2002). This paper argues that, rather than creating boundaries, the performative provides a figure - as a composite of performance and performativity - for thinking of the drawing process as a complex and dynamic assemblage. Performance in this paper is an apprehension that cannot be saved, recorded or documented; it pertains to visceral relations that do not involve discourse (Phelan 1993: 146). Thus by looking at performance we are focusing on how the individual engages in bodily practice, how we perform everyday activities, such as drawing. Performance allows us to draw our attention towards the uncertainties of drawing in terms of flows, and it allows us to elaborate on these uncertainties and the complexity of relations that are involved in drawing. But it is not only the visceral dimension of performance that is important here, but also the materiality of the body and of the built. For Bolt the performance of matter occurs when matter, of the body or the built, dominates the act performed (Bolt 2004). 
The understanding of performativity in this paper, used to analyse the WhiteHouse, is a merging of performance with notions of performativity gained from Judith Butler. Butler initiates her line of thinking of gender as performative in Gender Trouble (Butler 1990), where she proposes that gender is not about essences, but rather a doing. "Gender is itself a kind of activity...gender ought not to be conceived as a noun or a substantial thing or a static cultural marker, but rather as an incessant and repeated action of some sort" (1990: 112). In Bodies that Matter (Butler 1993), Butler takes her argument further and links the notion of performativity with citationality and the materialisation of the sexed body. Butler argues that materialisation emerges through the effect of iteration or citation of norms, but the consequence of this is that matter is reduced to its sign. Matter is left mute and without a history of its own. The actual busyness of making and acting in the world is left to slip away. The way we interact with the object world also slips, as Butler argues, for a split between notions of performance and performativity, between an act defined through agency and an act defined through discourse. As a result of this split between discourse and a body that acts within space and time, her work is unable to fully capture "kineasthetic vocabularies and imaginations" (Roach 1996). Thus in this paper, Butler's theory of performativity is extended by connecting it, intentionally, with the notion of performance, to discuss the specific practice of drawing and building. As Elin Diamond has written, when:

...performativity comes to rest on a performance, questions of embodiment, of social relations, of ideological interpellations, of emotional and political effects, all become discussable... When performativity materializes in that risky and dangerous negotiation between a doing (a reiteration of norms) and a thing done (discursive conventions that frame our interpretations), between someone's body and the conventions of embodiment, we have access to cultural meanings and critique. (1996: 5)

Performativity in this paper is thus rooted in the materiality, as well as the social density, of the architectural performance. Performativity provides us with a way of thinking about the grid of power relations which are institutional and structuring. Performance allows us a way to describe and analyse a class of actions, which emphasises "liminality over legibility and change over fixity [and which] is effective in placing interpretative emphasis on actions rather than on commodifiable objects" (Blocker 1999: 24) which occur at the level of the individual. This allows a complex theoretical framework to theorise the intra-actions between "material and discursive, social and scientific, human and nonhuman, and natural and cultural factors" (Barad 2003: 808). In the next section of the paper we explore this composite of performance and performativity by looking at the drawing of the White-House.

\section{Going through the project}

The first performance that takes place is the relationship between architect and client, a relationship that is as much discursive as it is embodied within the drawing. The clients' brief for this project was very specific in terms of how they wanted to live and work, and grew out of detailed conversations. Their everyday actions and protocols were recorded, along with their thinking about space, furniture and objects. The many complicated requirements and understandings of 

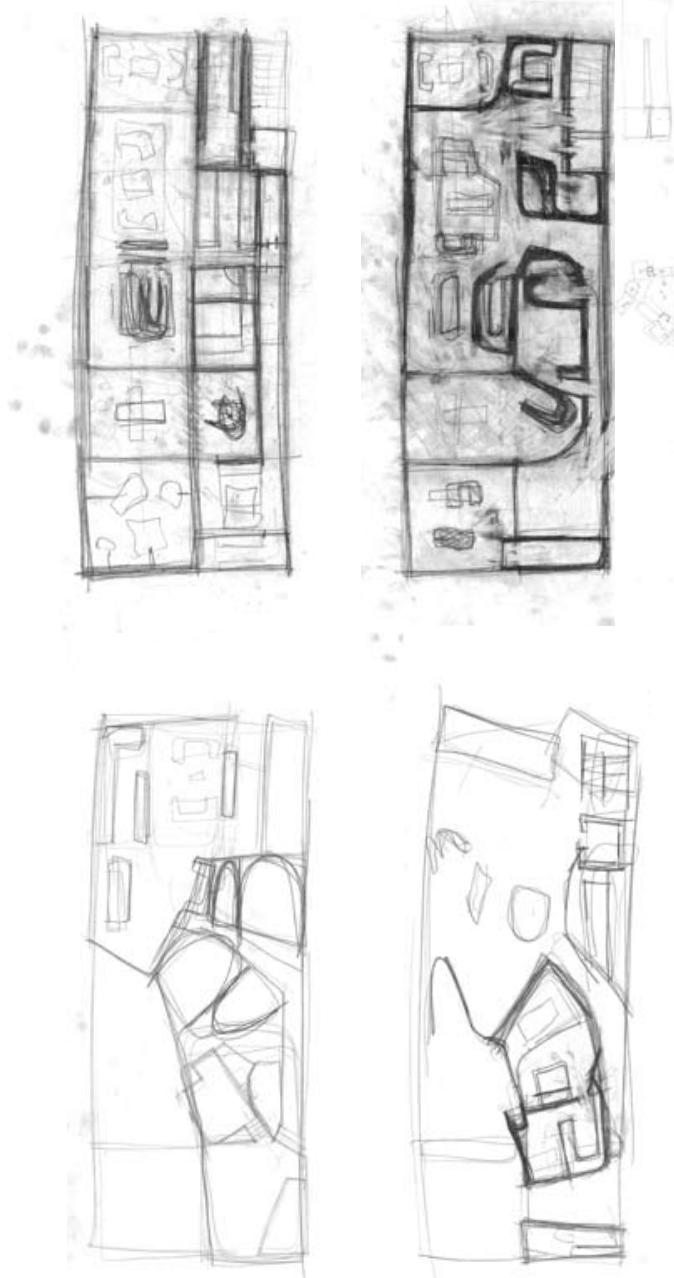
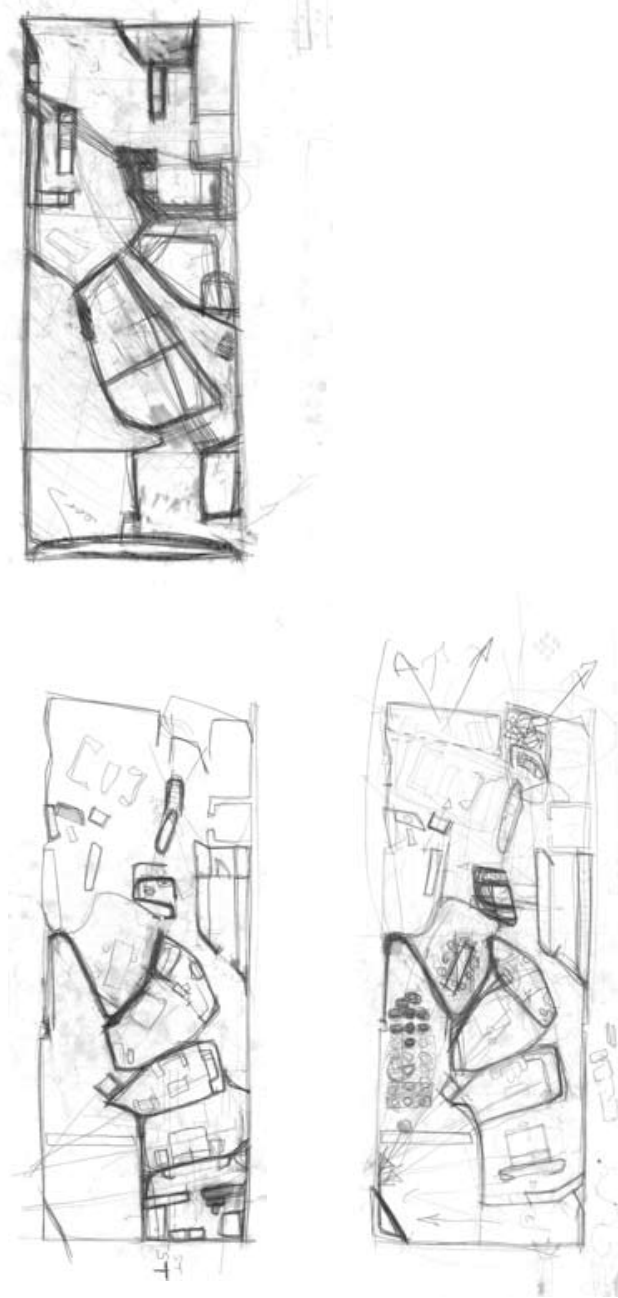

Early plan iterations, 1:50 sketch overlays, graphite on butter paper.

built space were accommodated in the drawings and, as the design progressed, the drawings were tested in real space: the clients moved around an improvised kitchen island, made on site from the nearest pieces of cardboard, they sat in folding chairs in the building site to check out the view, imagining they were relaxing in a comfortable living room, and so on. The clients went over every detail of how the spaces would be used, what they would be like, how people would react on entering them for the first time, how the spaces would speak of their professional abilities, how the building presented itself to the street, how it directed views towards the landscape - myriad interconnected complexities of space, object and action, negotiated in drawings. The plan moved in response to this performative process, which itself moved between performance and performativity.

The design began as a reasonably logical and orthogonal series of drawings ascribing functional areas normally associated with a house: bedrooms, kitchen, living room, hall, entry lobby. These initial drawings were crude $6 \mathrm{~B}$ sketches and were composed of reasonably straight lines, representing an assumed Euclidian accuracy that would occur in the built. In actuality the drawings were made up of many overlaid arcs and smudges attributable to the mechanics of the hand, arm and eye. Through the negotiated performance of the brief, the curvature inherent in that way of describing walls became more active, and the plan became a series of buckles and bulges. The plan became less of a diagram, of conventional divisions of function, and became more influenced by nuances of life and objects in space. The action of the hand and eye in the drawings was a parallel event to the projected events accommodated by the drawing - a kind of compositional alliance between the spatio-temporal of the built and the temporal space of drawing. There seemed to be compatibility between a responsive composition 
Developed plan, composite of separate drawings, 1:20, graphite on butter paper.

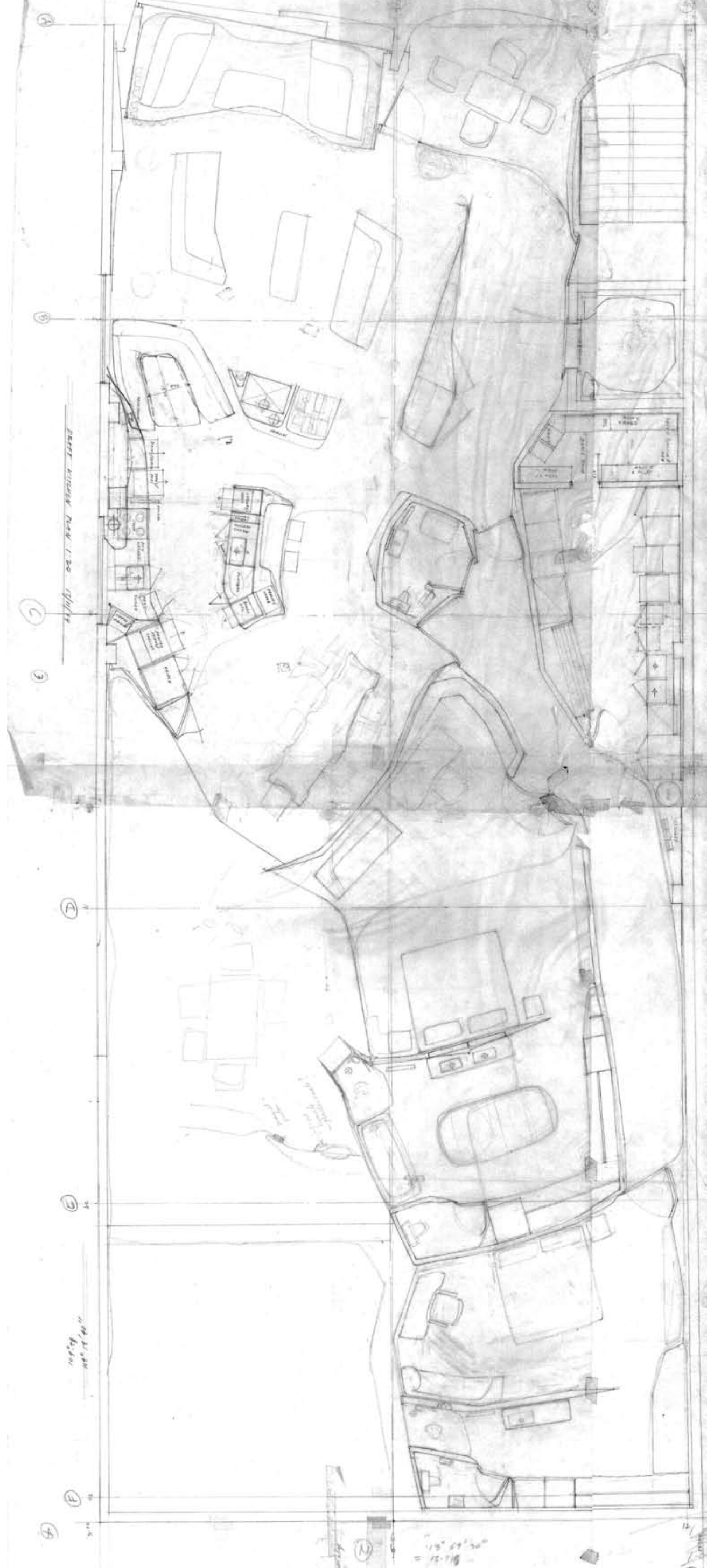


of arcs and curves, moved by objects and spaces competing for position, and the physical responsiveness of the body enacting the drawing. In turn this allied with a representational precedence taken from performative flows observed in the suburban city.

\section{Process}

While drawing, the design flattens on the drawing board into a self-contained world: successive iterations of butter paper drawings build on top of one another, often with the same shapes reinforced again and again, with only subtle variation. There is usually something in the bundle of lines and paper that is suspected to be there but refuses to come out. This process can be its own compositional confinement, locking the drawer into the space of the drawing. In this sense, meaning slips through a process of iteration and the composition becomes directed by the contained physical context of drawing. The layers of translucent butter paper make for a blurry palimpsest that gets thick enough to gain its own topography which, when the Mutoh's scales are rested on, they plump into. At times, these many sheets are separated and laid out in a sequence, forming a drawn history of small decisions and quirks that can be viewed together - and selected parts are recombined and taped back onto the drawing board.

This iterative drawing process engages iterations of space: dense layering, expanding, recombining - and the making of them involves many movements and proximities of body to paper. Within the iterations there exists the possibility of disrupting notions of habit or norm. For Butler, the disruption of norms occurs in terms of discourse or discursive practices rather than in terms of matter itself. Clearly the matter of the body and of the drawing through these iterations has its own material presence. Each arc of the hand on the paper, each performance, each repetition, involves different flows, and different connections, so that each repetition is always a singular behaviour (Bolt 2004: 156). Matter has a presence. Matter has a force. Moreover matter here is productive, a productive materiality: a type of performative materiality.

Drawings are fields of movement, in the way they record not only movement of the pencil, but also movement of viewpoint: eye and paper, a performance between me and the space internal to the process of design. One's proximity to the paper varies, and movements between close and far attention correspondingly adjust perceptual relations to the drawing. When closely engaged in a small part of a large drawing there is pleasure in the limited field of view and the reduction in understanding of the whole - the drawing becomes about elements and junctions and qualities of line, active relationships at detail level. Standing back, the composition of parts is seen together, in the conventional manner, and one's understanding of the drawing at that proximity is tied to the active space around it, of the interaction between oneself and the drawing at a distance. At a distance, it can also be viewed obliquely, which opens another understanding of the design, different from the perpendicular attention of the drawing on the board. In the White-House, this oblique view was exaggerated in the construction set-out: the plans were drawn by hand on the concrete floors, using flexible timber sticks and improvised compasses. The one-to-one drawing was adjusted by hand-drawn arcs, as a large composition, and the drawing "walked through" as a final check

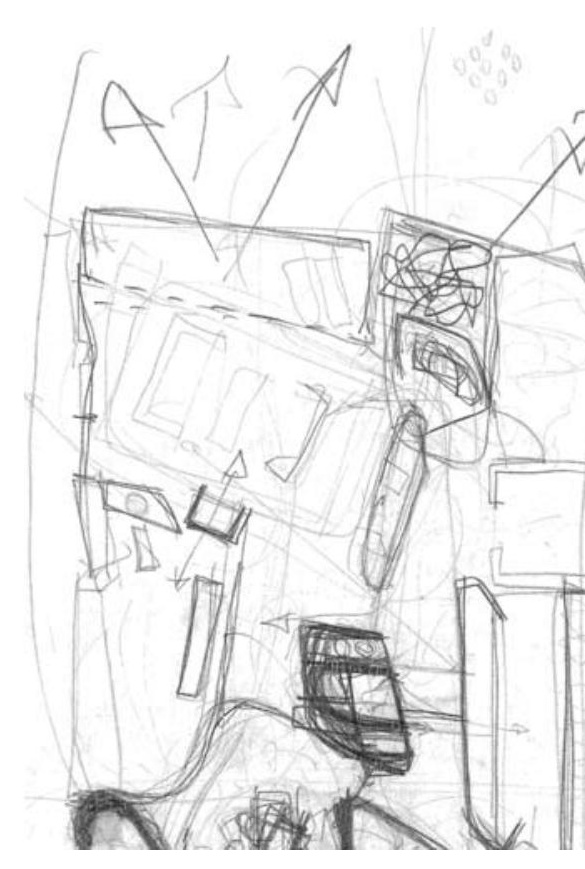

Detail plan, 1:50 sketch overlay, graphite on butter paper. 
of qualities sketched earlier on a smaller scale. The architect's bodily engagement with the drawing process was activated by affective registers of the materials the drawing was meant to govern.

The drawing becomes the trace of the body's movement: the shifting of focus, the lightness of touch, the heaviness of repeated lines; varying pressures are made evident across the paper. But, quite literally, the production of the drawing requires the body, a body that is moving and is performing - where the body itself, for Bolt, undermines the apparent truth of representation (Bolt 2004: 51). But matter here, the matter of drawing, is still pressing against the body, impressing on the body. It is a dynamic exchange that occurs between drawing and the dynamism of the human body (Bryson 1983: 137).

I (Twose) was also involved in the physical making of the project, where once again it is the performative body that works to undermine the truth of representation. Similar to the hand-drawn set-out, the making of the ceiling doubled the design process with its built concomitant, and the three-dimensional curves of the ceiling were moulded by hand like a large model. The ceiling was designed as a soft moderator of many heights, all the doors were different heights and, being floor-to-ceiling, the ceiling draped over them; the spaces had different degrees of spatial generosity, and competing heights met at the central toilet. This was very difficult to describe in drawing and was physically modelled but in the end the only way to understand the ceiling was to hang a flexible ceiling grid in the space, get up on a ladder and physically manipulate the grid until the curves were right. The ceiling was "worked on" as if it were a large sheet of paper, only this time it was above my head and had gained the resistance of mass and unmanageable proportions. The ceiling as a terrain, overhead instead of underfoot, directly related to the terrains of paper that hosted the design thinking. Moreover the ceiling had an insistence - within the operation of the meaning of
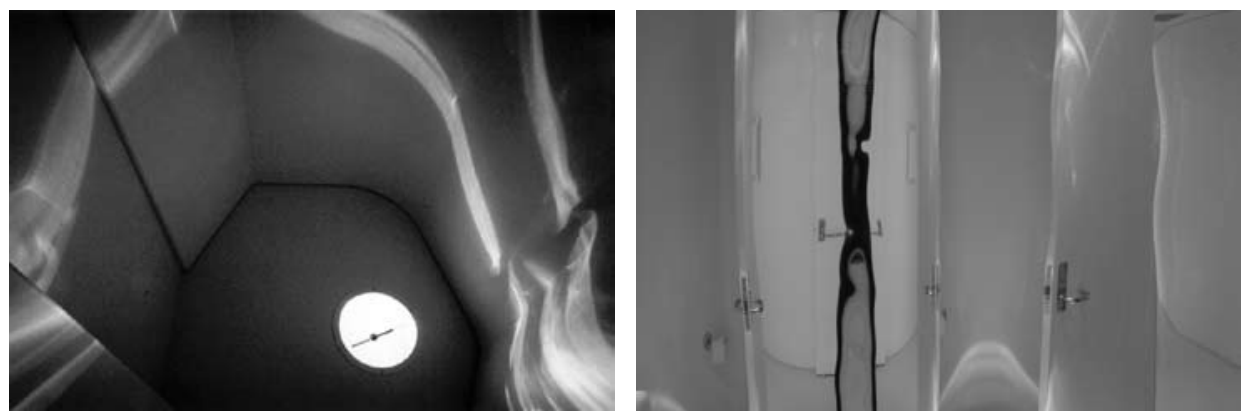

the built (Benjamin 1996: 47). The ceiling was a dynamic object. In this performative framework the environment, objects and bodies are no longer passive - instead it (not clear what 'it' is referred to) allows us to focus on the muddying of boundaries between human and non human, drawing and building, that causes mixtures or assemblages to occur (Rajchman 1998: 60, Thrift \& Dewsbury 2000: 418). These occur between the body working the material and the insistence of the matter of the ceiling; there is a mutual reflection here that is not just a oneway causality of the human.

So the performative can be understood in terms of the relationship between client-drawing and the body-drawing but it is clearly evident in the exchange between building-drawing - as that which enacts or produces a drawing and 

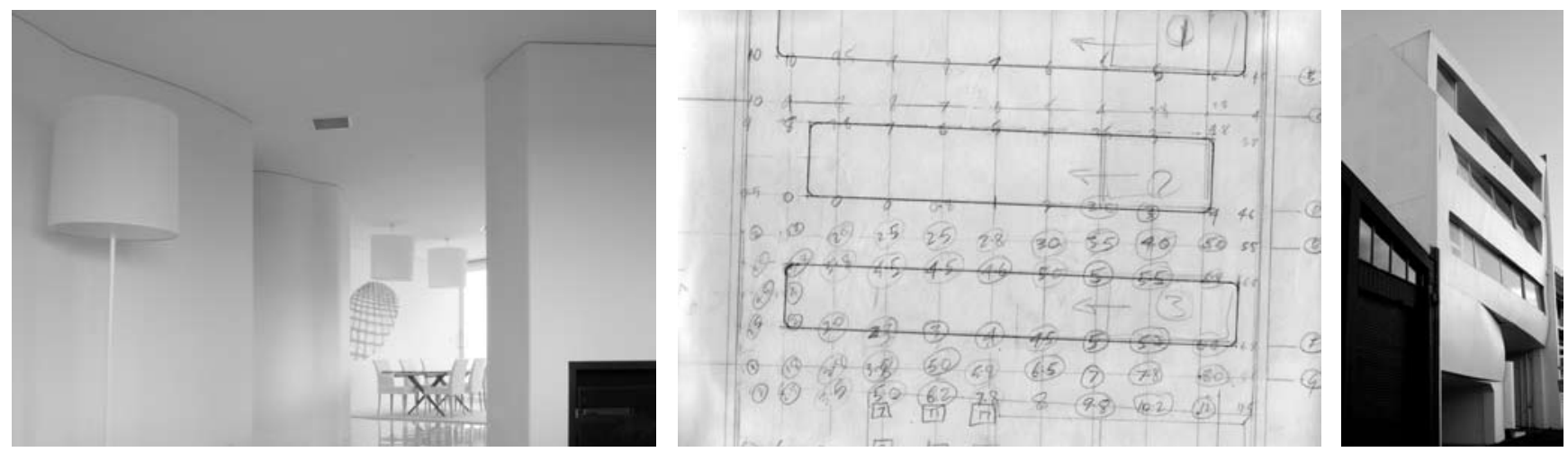

also a building. As already alluded to, this is a shift in the position that says: for drawing to be performative it must be separated from the built. Light, for example, normally a clarifier of form, in this case is the agent of soft, drawinglike indeterminacy. The white walls, floor and ceiling are swamped in reflected light, which makes for a foggy boundary to the space and supports distortion as an event. The distorted surfaces are physically static but their curvature gives an impression of temporality; they are this shape but could be another shape, along some continuum of distortion over time. The temporal movements of the drawing process are palpable and the building has the sense of potentiality of a sketch. The drawing and the body are infolded enfolded into the immanent imminent potential of the built.

Another example of a performative relationship between drawing and building is found in the central toilet space. The centrally-located toilet was the meeting place of varying competing forces in the programme, and as a result is the most crumpled part of the building. Inside the toilet, a curved mirror follows the wobble of the walls and, if you are not used to it, has a disconcertingly queasy effect. It is a curiously direct physiological feedback, from room to person, of the distorting forces of programme that shaped the plan: images of your body are stretched apart like chewing gum by the mirror and re-assembled as narrow figures in the tighter concave corners. The body here shifts more towards a drawn object. Furthermore, the doors around the toilet push their way into the skin of the toilet walls. The walls curve into the door jambs, which reduces the tectonic and technical drama of the openings: rather than a door being a break in the wall, the wall surfaces are directed from one space to another along a curved route, around the curved jamb detail. The open leaves also slightly indent the walls they rest against. A sfumato light to the door edges helps in softening the rupture of the walls and the detail reduces the emblematic "doorness and realness" of the door and, consequently, the space. The space is more like an inhabited drawing, like being within a superficial thinness, which appears to have a trajectory.

The detailing in general was carefully designed to give this impression - to reduce the seriousness and finality of a built architecture. Things indicating building were reduced or eliminated: junctions between elements were made as simple as possible; there are no skirtings, no window sills, no apparent material to anything other than white, edges were detailed to give an impression of thinness and insubstantiality - everything was designed to give an impression of the provisional or possible, as in a drawing.

\section{White}

A further example of this performative exchange between the building and drawing is found in the exploration of colour. The surface of every element in the space is white, or is meant to be white, there being innumerable variations. The walls are painted in a flat white, with little texture. The floor is painted in 
gloss white; the ceiling is velvet white. The furniture (curved and purpose-made to suit the spaces) is velvet white Formica, all the appliances and windows are "appliance white", the façade is a low-sheen white, matched from the Formica sample; the courtyard and loggias are a similarly uncompromising white. This treatment of the surfaces and objects gives an immaterial soft fog to the spaces. Hierarchies between elements are reduced by the flat whiteness and there is a sense of merging of things which normally have a discrete identity: furniture is not framed by space but somehow in collusion with it, the bath has a white lid to acknowledge its usefulness as a seat - and is built in to the floor and wall surface - the layered white curtains are flimsy versions of the walls. Conventions of orientation and weight are softened by the velvet white: wall is floor is ceiling - and when one moves through it, it is as if the building could be turned upside down like a large model and rotated to check the light. The soft texture of the surfaces, turning into the door edges or undulating down the hall, have a scaleless characteristic, with nothing to reference them in size or distance; they recede as you approach. The fuzzing of the surface texture works with soft curvature to maintain an atmosphere of provisional space, and alludes to an atmosphere of drawn space. Moreover, the relationships between objects, architecture and the body are unstable, they are dynamic, and no longer defined by fixed relations that denote identity. Rather, the differing relationships between architecture, objects and furniture create new connections. In this way they belong to a dynamic rather than static understanding of architecture.

It must be acknowledged that this sounds like a typically modernist strategy - of a unifying abstract whiteness - but the surfaces here are very different to abstract Euclidean ideals: it is evident they are distorted by some invisible process, the result of weird forces of negotiation, rather than composed with pre-conceived geometries. Because of this, the house has an uncomfortable, comfortable sense - it is shaped by the needs of comfort without resembling architecture's normal mode of providing it. When in the real space, it seems serene and undistracting, being curved and white - but there is also a sense of dislocation from the real. The materials seem to be, predominantly, light and time; nothing seems fixed, or of fixed substance. It is "like inhabiting an idea", life tracing over drawn life, where the dynamic relations between drawing, building and the body continue to resonate off each other in constantly shifting assemblages of relations.

In this case, the scuffing and smudging of architecture by life occurred in the drawing, and was suppressed in the building: the white surfaces are kept scrupulously clean and bear no marks - vacuum cleaners that might bump the skirting-less negative detail at the floor are kept away from the walls; a special swivelling broom is used to sweep around the curved junctions. This concern for a purity of occupation is a reversal of drawing and building - with the building maintaining an abstract purity while the drawings record the smudges and marks of use through their hand-drawn interactions and accommodation of potential future events.

There are many layers of process embodied within the drawing and the building, and it is in the practice of drawing and the practice of making architecture, hich architects performatively engage with, that reiterate norms of architecture - socially, economically and politically - of the particular historical moment (Bolt 2004). The statutory controls of architecture - codes, legislative acts and drawing conventions - all become naturalised alongside the practice of doing architecture. The arguments and frustrations of working against these discursive con- 
straints when designing are very much part of the drawings; they are normative relations embedded in the drawing process - the banality of the everyday. If we continue with Butler's line of thinking, the process of "materialization stabilizes over time to produce the effect of boundary or fixity of a surface" (Butler 1993: 9). So this enables a discussion of how conventions or the economics of constraint are enshrined and fixed, or are literal laws that overshadow the drawing process and are embedded within it. However, as was alluded to earlier, within Butler's framework of performativity, there is no way that she can account for materialisation that occurs between the matter of bodies, the materials of production and discourse (Bolt 2004: 153). Of course these codes are themselves never finite or fixed - they are up for negotiation.

Through this exploration, of the drawing of the White-House as performative, on the one hand what is highlighted is that each "repetition involves different intensities, different flows, and different connections, so that each repetition is always a singular behavior" (Deleuze 1990: 289). So, whilst Butler's account of performativity underplays this capacity to engender the transformation that is possible through material performance, framing performance, without performativity, and without constraints, runs the possibility of being framed as naive (Thrift \& Dewsbury 2000). Performance and performativity, when they form a composite of different modes of thinking, enable exchanges to be possible - indeed, this composite, this way of analysing the drawing process, highlights the dynamic intra-active relations that exist between body/building and drawing.

\section{Conclusion: intra-active possibilities}

The first part of this paper introduced performance and performativity, and highlighted that these terms are seen as theoretically distinct. Drawing was explored through an analysis using both notions - of performance and performativity. This composite analysis allows the complexity of drawing practice to be understood as an embodied and material performance, while at the same time not forgetting normative relations that inherently shape drawing. The WhiteHouse illustrates this performative state of drawing.

The final part of the paper concludes that, in theorising drawing through the lens of performance and performativity, our attention focuses on the assemblage of relations and intra-actions between drawing, building, the body and representation, and reveals them to be located, complexly, within and through each other. Indeed, it is the composite figure of performance and performativity that provides a way of thinking of the assemblages between drawing/body/building and their varied arrangements as "inseparable intra-acting 'components'" (Barad 2003: 815). This is a different proposition to exploring "interactions" between components, as this would imply that they are independent entities from the outset. This re-working of performativity allows an understanding of how drawing emerges - through various intra-actions with the body and the built (Barad 2003: 815).

So, rather than assuming that drawing is static and removed from the body and from the built, assemblages are understood as a "dynamic (re)configuring of the world's specific agential practices/intra-actions/performances through which specific exclusionary boundaries are enacted" (Barad 2003: 816). Thus, if we are to understand the drawing of the White-House as a dynamic process of intra- 


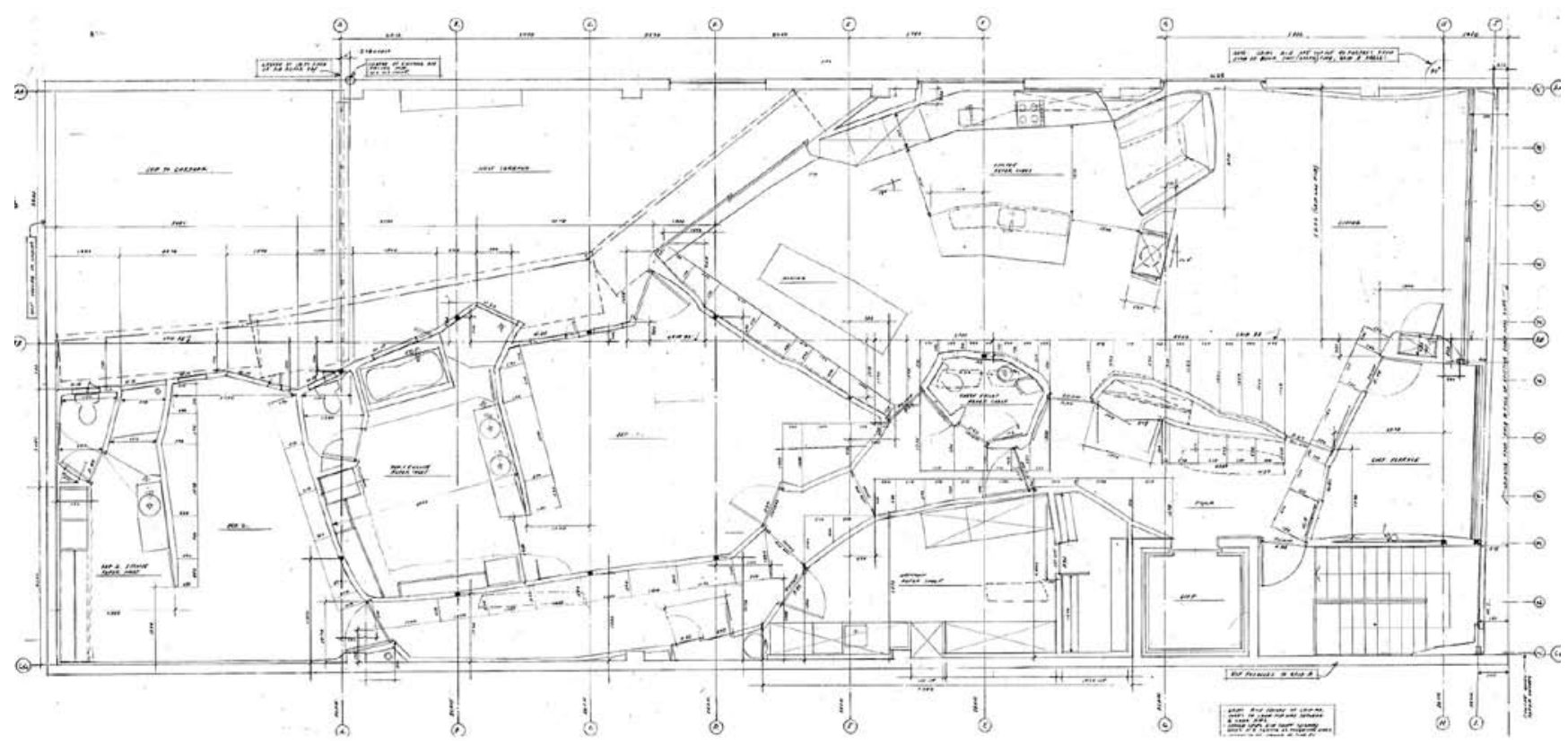

Plan, contract drawing, 1:20, graphite on film. activity, it becomes part of the ongoing "reconfiguring of locally determinate causal structures with determinate boundaries, properties, meanings and patterns of marks on bodies" (Barad 2003: 816). Thus, drawing and building, which are nominally assigned the role of non-human, start to shift in this framework as they are actualised through different intra-active possibilities. Drawing is no longer just an object. It is not dead matter but is in dynamic reconfiguration, entanglements and (re)articulations with the body and the built (Barad 2003: 818). Drawing is active in this process of intra-active assemblages - it is not a thing but a doing. Through this doing it has a congealing of agency, which has an effect. The important thing here - and what is not offered in Butler's theorisation, but rather within theories of performance - is a notion that matter is an active agent in its ongoing materialisation. Matter in terms of the drawn or the built is an active agent in the dynamics of intra-activity.

A composite of performance and performativity also provides a way of thinking of the intra-actions that occur between discursive and material performance. Butler's constructivist model is still fully implicated in the dynamics of intra-activity through which phenomena come to matter. Materiality is still discursive; to claim that it was not would run counter to the thread of this paper, which is trying to understand the dynamics of body/drawing/building/body as complex material and discursive relations that act as a site of exchange, of "intra-activity". So the material and the discursive are related through intra-activity, yet are still not reducible to each other. Neither one is privileged over the other. Codes and conventions of drawing and building, that inform the drawing and the building of the White-House, through intra-actions, are causally constraining yet still enfold further materialisation.

\section{References}

Austin, J. L. (1975). How To Do Things With Words. Oxford: Clarendon Press.

Barad, K. (2003). Post humanist Performativity: Toward an Understanding of How Matter Comes to Matter. Signs: Journal of Women in Culture and Society, 28, No. 3. 801-831, 815.

Benjamin, A. (1996). Matter's Insistence: Tony Sherman's Banquo's Funeral. Art and Design Profile, 48, no. 5 .

Blocker, J. (1999). Where is Ana Mendita: Identity, Performativity, and Exile. Durham and London: Duke University Press. 
Bolt, B. (2004). Art Beyond Representation: The Performative Power of the Image. London and New York: I. B. Tauris.

Bryson, N. (1983). Vision and painting: The logic of the gaze. London: Macmillan.

Butler, J. (1990). Gender Trouble: Feminism and the Subversion of Identity. New York: Routledge.

Butler, J. (1993). Bodies that Matter: the Discursive Limits of "Sex". New York: Routledge.

Campbell, D. (1992). Writing Security: United States Foreign Policy and the Politics of Identity. Minneapolis, MN: University of Minnesota Press.

Deleuze, G. (1990). Logic of Sense. M. Lester \& C. Strivale (Trans.), C. V. Boundas (Ed.). London: Athlone Press.

Denzin, N. (2001). The Reflexive Interview and a Performative Social Science. SAGE Publications, vol. 1(1), 23-46.

Diamond, E. (Ed.) (1996). Performance and Cultural Politics. London and New York: Routledge.

Conquergood, L. D. (2002). Performance Studies: Interventions and Radical Research. TDR: The Drama Review 46(2) (T 174) 145-156.

Evans, R. (1997). Translations from Drawing to Building. London: Architectural Association Publications.

Madison, D. S. \& Hamera, J. (Eds.). (2006). The SAGE Handbook of Performance Studies. California: Sage Publications, Inc.

McCormack, D. P. (2005). Diagramming Power in Practice and Performance. Environment and Planning D: Society and Space, 23(1): 119-147.

Nash, C. (2000). Performativity in Practice: Some Recent Work in Cultural Geography. Progress in Human Geography. 24, 653.

Nicholson, L. \& Seidman, S. (1995). Social Postmodernism: Beyond Identity Politics. New York: Cambridge University Press.

Parker, A \& Kosofsky Sedwick, E. (1995). Performativity and Performance. New York: Routledge.

Phelan, P. (1993). Unmarked: The Politics of Performance. London and New York: Routledge. Rajchman, J. (1998). Constructions. Cambridge, Mass: MIT Press.

Roach, J. (1996). Kinship, Intelligence, and Memory as Improvisation: Culture and Performance in New Orleans. In E. Elin Diamond (Ed.), Performance and Cultural Politics (217236). London: Routledge.

Steiner, B. (2003). Performative Architecture. In A. Nollert (Ed.), Performative Installation. Cologne: Snoeck.

Thrift, N. \& Dewsbury, J. D. (2000). Dead Geographies and How to Make Them Live. Environment and Planning D: Society and Space, 18, 411-432.

Tormey, J. (2010). How To Do Things With Drawing. Retrieved February 23, 2010, from http:// www.lut.ac.uk/departments/ac/tracey/perf1.html

Walker, J. A. (2003). Why performance? Why Now Textuality and the Rearticulation of Human Presence. The Yale Journal of Criticism, 16 (1).

Wood, P. (2002). Drawing the Line: A Working Epistemology for the Study of Architectural Drawing. Unpublished Dissertation for the Degree of Doctor of Philosophy, University of Auckland, Auckland. 